\title{
Anticorpos Anticardiolipina entre Gestantes com Óbito Fetal
}

\author{
Anticardiolipin Antibodies among Pregnant Women with Fetal Death \\ José Guilherme Cecatti, Márcia Maria Auxiliadora de Aquino, Eloana Maria Tintori, \\ Daniela Angerame Yela, Mary Luci de Souza Queiroz \\ RESUMO
}

\begin{abstract}
Objetivo: avaliar a prevalência de anticorpos anticardiolipina entre gestantes com óbito fetal intra-uterino.

Pacientes e Métodos: foi um estudo de corte transversal que avaliou 109 gestantes hospitalizadas com o diagnóstico de morte fetal intra-uterina e idade gestacional de 20 semanas ou mais, durante o periodo de maio de 1998 a setembro de 1999, da Maternidade da Universidade Estadual de Campinas e do Hospital Maternidade Leonor Mendes de Barros, em São Paulo. Estas mulheres foram submetidas a exames laboratoriais de rotina para a identificação da causa do óbito, incluindo a determinação sérica do anticorpo anticardiolipina, por meio dos niveis de IgG e IgM. Os resultados de IgG são expressos em unidades GPL e os de IgM em unidades MPL, sendo considerados positivos, nos dois casos, os valores acima de 10 unidades. Os procedimentos estatísticos utilizados foram o cálculo de médias, desvio padrão e comparação dos grupos por testes t de Student, Fisher e $\chi^{2}$.

Resultados: a prevalência de positividade para o anticorpo anticardiolipina foi de 18,3\%. As mulheres eram predominantemente jovens, com média de idade em torno de 27 anos. As principais causas identificadas de morte foram: hipertensão $(26,1 \%)$, hemorragia durante o terceiro trimestre de gestação (9,9\%) e malformação fetal (8,1\%). Em cerca de um terço dos casos, a causa da morte fetal não foi identificada. Considerando os 20 casos com positividade para anticorpo anticardiolipina, a proporção de causas não identificadas caiu para 29\%.

Conclusões: é importante determinar a presença de anticorpos anticardiolipina em mulheres com perdas fetais com o propósito de elucidar outras causas de morte fetal, especialmente a sindrome antifosfolipide e demais situações correlatas. Para estes casos é necessário o aconselhamento e o tratamento destas mulheres em gravidezes futuras.
\end{abstract}

PALAVRAS-CHAVE: Óbito fetal. Anticorpo anticardiolipina. Sindrome antifosfolipide. Hipertensão arterial.

\section{Introdução}

A sindrome do anticorpo antifosfolípide caracteriza-se pela presença de anticorpos antifosfolipides no soro de indivíduos com trombose arterial ou venosa, abortos recorrentes, óbito fetal ou trombocitopenia. É uma causa bem conhecida de hipercoagulabilidade e tem múltiplas manifestações, podendo ou não ser secundária a uma

$\overline{\text { Departamento de Tocoginecologia, CAISM/FCM/UNICAMP }}$ Hospital Maternidade Leonor Mendes de Barros Projeto parcialmente financiado pelo FAEP/UNICAMP Processo 0304/98.

Correspondência:

José Guilherme Cecatti

Caixa Postal 6030

13083-970 - Campinas - SP

Fax: (19) 239-3687 doença auto-imune ${ }^{1}$. Na prática, esta possibilidade surge secundariamente, após a investigação de causas mais comuns das manifestações apresentadas. Não raro, associa-se ainda a quadros atípicos de hipertensão arterial.

Inicialmente a síndrome foi descrita em pacientes com diagnóstico de lúpus eritematoso sistêmico. No entanto, hoje sabe-se que é mais encontrada em indivíduos sem qualquer outra alteração auto-imune (síndrome primária). O primeiro estudo prospectivo que definiu as características clínicas da síndrome antifosfolípide primária foi o realizado por Asherson et al. ${ }^{2}$.

A partir desta descrição inicial, estabeleceram-se critérios mais definidos para o diagnóstico desta manifestação, sendo os mais abrangentes os propostos por Alarcón-Segovia e SanchezGuerrero $^{3}$. Consideram que o diagnóstico é defi- 
nitivo na presença de altos títulos de anticorpos anticardiolipina (ACL), ou demais anticorpos antifosfolipides, associados a duas ou mais das seguintes manifestações clínicas: perdas embrionárias e/ou fetais recorrentes, trombose venosa, oclusão arterial, úlcera de membro inferior, livedo reticularis, anemia hemolitica e trombocitopenia ${ }^{4}$.

Os anticorpos antifosfolípides são imunoglobulinas que reagem contra fosfolipides de membrana carregados negativamente. O diagnóstico laboratorial da síndrome é possivel pela detecção de anticorpos que se ligam a fosfolipídeos ou ao complexo fosfolipídeo-proteína. Destes anticorpos, os que são mais pesquisados na prática são a anticardiolipina e o antilúpico dos tipos IgG e IgM, embora existam outros cuja detecção, no sangue ou em tecido placentário, é de mais dificil realização (fosfatidilserina, fosfatidiletanolamina, fosfatidilinositol, fosfatidilglicerol e ácido fosfatídico), ainda não disponíveis na prática no Brasil $^{5}$.

O teste para o anticorpo antilúpico é complexo, ao passo que o para a anticardiolipina é mais sensivel e de mais fácil realização. Ambos são de dificil interpretação. O teste para o anticorpo antilúpico é realizado em três etapas, a fim de mostrar o prolongamento da coagulação, via inibição da conversão de protrombina em trombina ${ }^{6}$.

Para o anticorpo anticardiolipina, o método utilizado é o ELISA. A interpretação é dificil porque pode ser positivo em situações de infecções e doenças inflamatórias, malignas e induzidas por drogas. Como variações na execução do exame podem levar a diferenças, deve-se quantificar os resultados e identificar os tipos de anticorpos detectados $^{6}$. Os resultados referentes às IgG são expressos em unidades GPL e às IgM em unidades MPL, sendo uma unidade GPL ou MPL correspondente à atividade de ligação de um $\mathrm{mg} / \mathrm{ml}$ do anticorpo IgG ou IgM, respectivamente.

Segundo a última padronização publicada por Harris et al. ${ }^{7}$, os resultados são expressos de forma semiquantitativa e considerados negativos se menores que 10 unidades GPL ou MPL/ml. Os resultados positivos, por sua vez, são subdivididos em fracos, entre 10 e 29 unidades GPL/ml ou MPL/ $\mathrm{ml}$, moderados, entre 30 e 60 unidades GPL $/ \mathrm{ml}$ ou MPL/ml e fortes, acima de 60 unidades GPL/ $\mathrm{ml}$ ou MPL/ml.

O diagnóstico laboratorial de síndrome antifosfolipide é mais provável na presença de títulos moderados a altos (acima de $30 \mathrm{U}$ ) de IgG ou IgM anticardiolipina, expressos em unidades GPL e MPL, respectivamente ${ }^{8}$.

A sindrome antifosfolípide, em Obstetrícia, associa-se a perdas fetais recorrentes (abortamen- tos ou óbitos fetais), patologias placentárias (vilites, vilosites, tromboses, intervilosites), doença inflamatória pélvica, endometriose, antecedente de infertilidade, insucesso em tratamento de esterilidade e outras condições ${ }^{5}$.

Os fosfolipides são fundamentais para a implantação placentária porque são responsáveis pelas ligações celulares do citotrofoblasto ao sinsiciotrofoblasto. Isto explicaria os abortamentos recorrentes em mulheres com anticorpos antifosfolipides ${ }^{5}$.

A perda fetal no segundo e terceiro trimestres de gestação é um dos eventos mais relatados da sindrome antifosfolipide. Quando a morte fetal ocorre, é importante a identificação de sua causa, seja porque os pais têm o direito de ter conhecimento de como e porquê os fetos morreram, seja porque o conhecimento da causa da morte pode ser relevante para uma gravidez futura. Entretanto, mesmo com a utilização de protocolos detalhados de investigação da causa da morte, nem sempre isto é possivel: 12 a $50 \%$ dos casos acabam classificados como de causa indeterminada ${ }^{9,10}$

Estudo realizado em São Paulo, no período de agosto de 1996 a maio de 1997, para investigação de causas de morte fetal em 122 gestantes com este diagnóstico, utilizou um extenso protocolo, incluindo exames laboratoriais, necrópsia dos recém-nascidos e exame histológico da placenta, mostrando que hipertensão arterial e infecções foram as principais causas identificadas de morte fetal, ao passo que em um quarto dos casos a causa não foi determinada. Mostrou também a necessidade de se adicionar à investigação o estudo citogenético do recém-nascido e a avaliação da presença de anticorpos antifosfolípides no soro materno para aumentar o número de causas identificadas, diminuindo o de causas indeterminadas ${ }^{11}$.

O mecanismo fisiopatológico da síndrome antifosfolipide na perda fetal inclui a ação destes anticorpos nas células endoteliais, levando a agregação plaquetária, trombose, infartos placentários e subseqüente redução da oxigenação fetal ${ }^{12}$.

Em 1985, Lockshin et al. ${ }^{13}$ associaram a ocorrência do sofrimento fetal com anticorpos anticardiolipina em mulheres lúpicas. Já no estudo de Bocciolone et al. ${ }^{14}$, os níveis de anticorpos anticardiolipina em mulheres sem evidência clínica de lúpus eritematoso sistêmico ou outras doenças auto-imunes, que evoluíram com óbito fetal, foram significativamente mais altos do que em mulheres que tiveram pelo menos um filho nascido vivo, saudável e a termo.

A partir de então, vários estudos têm mostrado a associação entre anticorpos antifosfolípides e perda fetal ${ }^{15}$. Sua prevalência na morte fetal re- 
corrente pode variar de 10 a $48 \%{ }^{12}$, dependendo da população estudada e dos métodos laboratoriais utilizados. Atualmente é possivel predizer que mulheres com titulos moderados ou altos de anticorpos anticardiolipina do tipo IgG têm maior risco de perda fetal e que este risco aumenta se já houver este antecedente ${ }^{16}$

Segundo Kwak et al. ${ }^{5}$ a prevalência de anticorpos anticardiolipina nas situações de perdas fetais recorrentes é de 7\%, mostrando que somente a investigação deste anticorpo não é suficiente para o diagnóstico de síndrome antifosfolípide. Outros autores têm mostrado que mulheres com história clínica de síndrome antifosfolipide, mas com anticardiolipina e antilúpico negativos, devem ter seu soro testado para outros anticorpos antifosfolípides ${ }^{17}$.

A importância do reconhecimento desta síndrome pelos obstetras está na necessidade de tratamento durante a gestação destas mulheres com aspirina em baixas doses (50 mg/dia) e heparina subcutânea, procedimentos que previnem o retardo de crescimento intra-útero e a morte fetal. Em estudo realizado na Espanha, administrou-se aspirina em baixa dose $(50 \mathrm{mg} / \mathrm{dia}) \mathrm{du}-$ rante toda a gestação em 28 mulheres com perdas fetais. O tratamento revelou-se seguro e eficaz, seja para conseguir uma gestação com sucesso, seja para reduzir os níveis de anticorpos anticardiolipina ${ }^{18}$. Nesta investigação, o índice de sucesso gestacional foi de $86 \%$.

Outro estudo mostrou ainda que esta terapia profilática provê um índice de sucesso de $77,8 \%$ e que este resultado é influenciado pelo número de perdas fetais prévias e títulos de anticorpo anticardiolipina ${ }^{19}$.

Neste sentido, o objetivo deste estudo foi avaliar a prevalência de anticorpos anticardiolipina no plasma de uma população de gestantes brasileiras com óbito fetal intra-uterino na segunda metade da gestação, comparando os grupos com e sem esse anticorpo sérico.

\section{Pacientes e Métodos}

Foi um estudo de corte transversal que avaliou 109 gestantes hospitalizadas com diagnóstico de morte fetal após a vigésima semana de gravidez. Este estudo foi secundário ao estudo já referido que procurou estudar de maneira extensa as causas de morte fetal em uma população brasileira de baixa renda ${ }^{11}$.

A amostra foi selecionada segundo a ordem de internação no Setor de Admissão do Hospital Maternidade Leonor Mendes de Barros, em São Paulo, e da Maternidade do Departamento de
Tocoginecologia da Faculdade de Ciências Médicas da Universidade Estadual de Campinas, no periodo entre maio de 1998 e setembro de 1999. Foram incluídas gestantes com diagnóstico de óbito fetal ocorrido antes do início do trabalho de parto e idade gestacional igual ou superior a vinte semanas. O protocolo foi previamente aprovado pelos Comitês de Ética das instituições.

Para a coleta de dados utilizou-se um formulário no qual constavam dados sócio-demográficos, clínicos e os resultados de alguns exames laboratoriais, incluindo a determinação do anticorpo anticardiolipina dos tipos IgG e IgM em unidades GPL ou MPL, respectivamente. Os instrumentos foram revisados quanto à qualidade $\mathrm{e}$ legitimidade das informações, e os dados codificados e armazenados em arquivo de computador, após testes de consistência.

A determinação destes anticorpos foi feita pelo método de ELISA, de acordo com descrição original de Harris et al. ${ }^{20}$, com modificações de Gharavi et al. ${ }^{21}$. O método consiste basicamente em revestir os orificios da placa de cultura com cardiolipina dissolvida em etanol $(50 \mu \mathrm{g} / \mathrm{mL})$, deixando evaporar a $4^{\circ} \mathrm{C}$. Após lavagem com PBS e bloqueio da reação com soro bovino adulto (SBA) a $10 \%$ em PBS, acrescenta-se o soro teste diluído 1:50 em 10\% SBA. Após incubação e lavagem, os anticorpos ligados aos fosfolipídeos são detectados pela adição do conjugado de IgG e IgM (Sigma) diluídos em SBA a 10\% em PBS. A densidade óptica é lida após completar a reação pela adição de substrato cromógeno p-nitrofenilfosfato e tampão de dietanolamina.

Procedeu-se então à análise descritiva dos dados referentes às prováveis causas de óbito fetal e às características sócio-demográficas e gestacionais das mulheres, segundo a prevalência de positividade de anticorpos anticardiolipina. Os procedimentos estatísticos utilizados foram o cálculo de média e desvio padrão, testes estatísticos de $t$ de Student, Fisher e $\chi^{2}$. Utilizou-se o pacote estatístico Epi Info 6.04.

\section{Resultados}

As mulheres estudadas eram jovens, com média de idade em torno de 27 anos, e idade gestacional média de 29 semanas. Eram em média tercigestas, com paridade média em torno de 1,5. Mais de um quarto das mulheres tiveram um ou mais abortamentos anteriores (Tabela 1).

Quanto aos antecedentes clínicos e obstétricos, observou-se que a hipertensão arterial esteve presente em torno de um quarto das mulhe- 
res e quando investigada na gestação atual esta cifra subiu para 35\%. Quando se compararam estes antecedentes em relação aos dois grupos pela positividade à $\mathrm{ACL}$, não se observou diferença estatisticamente significativa (Tabela 2).

Tabela 1 - Média de algumas variáveis demográficas, obstétricas e tempo de óbito das gestantes com óbito fetal de acordo com a positividade da anticardiolipina

\begin{tabular}{|c|c|c|c|c|c|}
\hline \multirow[b]{2}{*}{ Variáveis } & \multicolumn{2}{|c|}{$\mathrm{ACL}(+)$} & \multicolumn{2}{|c|}{ ACL (-) } & \multirow[b]{2}{*}{$p$} \\
\hline & Média & DP & Média & DP & \\
\hline Idade (anos) * & 26,5 & 7,2 & 27,0 & 6,5 & 0,775 \\
\hline Idade gestacional (sem) * & 29,4 & 5,6 & 29,6 & 5,5 & 0,844 \\
\hline $\mathrm{N}^{0}$ de gestações ** & 3,0 & 1,9 & 3,0 & 2,6 & 0,530 \\
\hline Paridade ** & 1,5 & 1,3 & 1,6 & 2,5 & 0,574 \\
\hline $\begin{array}{l}\text { №. de abortamentos } \\
\text { prévios** }\end{array}$ & 0,5 & 1,0 & 0,4 & 0,9 & 0,629 \\
\hline Tempo de óbito (dias) ** & 2,6 & 3,1 & 2,4 & 3,3 & 0,744 \\
\hline
\end{tabular}

Tabela 2 - Distribuição das gestantes com óbito fetal, segundo antecedentes clínicos e obstétricos.

\begin{tabular}{lcr}
\hline & ACL (+) & ACL (-) \\
\hline Antecedentes clínicos * & 3 & 24 \\
Hipertensão arterial & 1 & 4 \\
Diabetes & 0 & 1 \\
Cardiopatias & 3 & 9 \\
Outras & 13 & 51 \\
Ausentes & & \\
Patologias obstétricas atuais ${ }^{* *}$ & 5 & 33 \\
Hipertensão arterial & 1 & 4 \\
Diabetes & 1 & 2 \\
Malformação fetal & 1 & 1 \\
Isoimunização Rh & 3 & 10 \\
Outras & 9 & 39 \\
Ausentes & & \\
Total $(n)$ & 20 & 89 \\
\hline SIM X NÃO $\chi^{2} \quad{ }^{*} p=0,703$ & 0,878 &
\end{tabular}

Apenas cerca de $18 \%$ dos casos tiveram causa certa e em aproximadamente $47 \%$ puderam ser determinadas as causas prováveis de morte fetal. De todas as causas isoladas, a mais prevalente foi a hipertensão arterial (26,1\%). Foram observados 11 casos de descolamento prematuro de placenta, todos associados a hipertensão arterial. Somados aos 29 casos em que a causa provável foi hipertensão, em 36\% dos casos de morte fetal a hipertensão arterial esteve presente como fator etiológico. $\mathrm{Na}$ seqüência, as três causas mais prevalentes foram hemorragias do terceiro trimestre, malformações fetais e diabetes. Em cerca de um terço dos casos não houve definição da causa da morte (Tabela 3).

Tabela 3 - Distribuição percentual das mulheres, segundo as causas de óbito fetal.

\begin{tabular}{lcc}
\hline Causas & $\mathbf{n}$ & $\%$ \\
\hline Indeterminadas & $\mathbf{3 6}$ & $\mathbf{3 3 , 0}$ \\
Possíveis & 2 & $\mathbf{1 , 8}$ \\
$\quad$ Anemia & 1 & 0,9 \\
Drogas (crack) & 1 & 0,9 \\
Prováveis & $\mathbf{5 1}$ & $\mathbf{4 6 , 8}$ \\
Cardiopatia materna & 1 & 0,9 \\
Hipertensão & 29 & 26,1 \\
Diabetes & 4 & 3,6 \\
Alterações do cordão umbilical & 2 & 1,8 \\
Malformação fetal & 9 & 8,1 \\
Insuficiência placentária & 1 & 0,9 \\
Hidropisia fetal & 2 & 1,8 \\
HIV & 1 & 0,9 \\
ITU & 1 & 0,9 \\
Corioamnionite & 1 & 0,9 \\
Certas & $\mathbf{2 0}$ & 18,3 \\
DPP & 11 & 9,9 \\
Toxoplasmose & 2 & 1,8 \\
Cardiopatia fetal & 3 & 2,7 \\
Isoimunização Rh & 2 & 1,8 \\
Acidente de cordocentese & 2 & 1,8 \\
(n) & 109 & \\
\hline
\end{tabular}

Entre os métodos utilizados para a indução do parto, o misoprostol foi o mais prevalente, seguido pela ocitocina. Quanto à via de parto, predominou a vaginal, em cerca de $85 \%$ das vezes, tendo a cesárea sido utilizada em 16 casos (Tabela 4), sendo 11 por iteratividade e 5 por falha de indução.

Tabela 4 - Distribuição percentual das gestantes com óbito fetal segundo o método de indução e via de parto.

\begin{tabular}{lrr}
\hline Método & $\mathbf{n}$ & $\%$ \\
\hline Método de indução & & \\
$\quad$ Misoprostol & 43 & 39,4 \\
Ocitocina & 17 & 15,6 \\
Misoprostol + ocitocina & 7 & 6,4 \\
Outros & 4 & 3,7 \\
Nenhum & 38 & 34,8 \\
Via de parto & & \\
Vaginal & 93 & 14,7 \\
Cesárea & 16 & \\
Total (n) & 109 & \\
\hline
\end{tabular}


A prevalência de positividade para anticorpos anticardiolipina foi de 18,3\% (Tabela 2). Dos 20 casos, 6 estiveram associados a hipertensão arterial na gestação, 1 a isoimunização Rh, 5 a malformação fetal, 3 a outras causas e apenas 4 a nenhuma outra alteração possivelmente relacionada ao óbito fetal.

\section{Discussão}

O presente estudo foi realizado pelo interesse em elucidar um maior número de causas de óbito fetal. Este estudo foi secundário a uma investigação que estudou de forma extensa as causas e fatores de risco de óbito fetal em uma população brasileira de baixa renda ${ }^{11}$.

Os resultados mostraram que a principal causa de morte fetal foi a hipertensão arterial e que, em cerca de $33 \%$ das mortes, a causa permaneceu indefinida, indice este que caiu para $29 \%$ quando se considerou a positividade para anticorpos anticardiolipina como possivel causa. Apesar de esta redução ser relativamente pequena, é provável que fosse maior se se investigassem todos os demais anticorpos antifosfolipides. Além disso, contribui-se também ao esclarecimento da causa fundamental.

Ter encontrado a hipertensão arterial como a principal causa de óbito fetal nesta população não surpreende, já que outros estudos realizados em países em desenvolvimento identificaram essa mesma causa e o mesmo ocorreu no estudo já referido que antecedeu esse ${ }^{11,22,23}$.

Em relação às hemorragias do terceiro trimestre como causa de óbito fetal, os autores relatam taxas que variam de 10 a $19 \%$, sendo que neste estudo em torno de $10 \%$ das mortes fetais foram atribuídas a esta causa ${ }^{11,23}$.

A prevalência de anticorpos anticardiolipina em mulheres com óbito fetal encontrada neste estudo está de acordo com a maioria dos estudos que mostram taxas variando entre 10 e $48 \%{ }^{12}$. Entretanto, até onde vai nosso conhecimento, é o primeiro estudo brasileiro a encontrar prevalência tão elevada.

Com a determinação da presença de anticorpos anticardiolipina no soro materno dessas mulheres conseguiu-se reduzir em 10,0\% a taxa de causas indeterminadas. No entanto, é provável que esta cifra se reduzisse ainda mais se pudesse ter sido feita a dosagem de todos os anticorpos antifosfolipides, além do anticorpo anticoagulante lúpico.

Como a técnica de realização é mais fácil e o custo menor, a determinação do anticorpo anticardiolipina tem sido realizada para o diagnóstico de sindrome antifosfolípide. Porém, vários estudos têm mostrado a presença de outros anticorpos antifosfolipides em mulheres com fatores obstétricos desta sindrome, cujo resultado para anticardiolipina é negativo ${ }^{17}$.

Estudo realizado nos Estados Unidos da América, em 1996, mostrou que anticorpos anticardiolipina foram detectados em $17,3 \%$ de mulheres com perdas fetais recorrentes, comparado com somente $4 \%$ na população controle. Das mulheres com perdas, $10,1 \%$ foram negativas para anticorpos anticardiolipina, mas positivas para outro anticorpo antifosfolipide. Os autores enfatizam a necessidade de padronização da técnica, implantação de controle de qualidade, padronização da interpretação de resultados positivos e utilização de determinação de outros antifosfolípides, além da anticardiolipina ${ }^{24}$.

Este estudo mostrou que, em uma população brasileira de baixa renda, com pelo menos um óbito fetal, a prevalência de anticorpo anticardiolipina está em torno de 18,0\%. Mostrou ainda que as causas mais prevalentes de morte fetal anteparto no Brasil continuam sendo passiveis de controle e/ou tratamento. Nos casos em que a causa é indeterminada, a adição à investigação da positividade para anticorpos antifosfolipides possibilita um maior índice de causas prováveis e orienta o obstetra para uma possivel terapêutica na gestação, que, apesar de pouco avaliada em relação à eficácia, têm mostrado resultados bastante estimulantes ${ }^{18,19}$.

\section{Agradecimentos}

Sueli Cristina de Oliveira e Raphael Marcos Pereira, técnicos do Laboratório do Hemocentro da UNICAMP que realizaram, respectivamente, as determinações laboratoriais do anticorpo anticardiolipina e a revisão sobre a técnica laboratorial utilizada.

\section{SUMMARY}

Purpose: to evaluate the prevalence of anticardiolipin antibody in women with stillbirth.

Patients and Methods: this was a cross-sectional study performed from May 1998 to September 1999 at the Maternity of the University of Campinas and at the Hospital and Maternity Leonor Mendes de Barros, in Brazil, which evaluated 109 pregnant women hospitalized with the diagnosis of intrauterine fetal death and gestational age of 20 or more weeks. These women underwent some laboratory examinations to identify the cause of fetal death, including anticardiolipin antibody evaluation performed through the 
determination of IgG and IgM serum levels. IgG and IgM results are expressed as GPL and MPL units, respectively, and, in both cases, results above 10 units are considered positive. The statistical procedures used were the mean and standard deviation estimates, Student's t test, Fisher test and $\chi^{2}$.

Results: the prevalence of anticardiolipin positivity was $18.3 \%$. The women were predominantly young, with a mean age around 27 years. The main identified causes of fetal death were: hypertension (26.1\%), hemorrhage during the third trimester (9.9\%) and fetal malformation (8.1\%). One third of the cases had no identified causes of fetal death. However, considering the 20 positive cases for anticardiolipin antibody, the proportion of unidentified causes decreased to $29 \%$.

Conclusions: it is important to investigate the presence of anticardiolipin antibodies among women with intrauterine fetal death with the purpose of clarifying the causes of stillbirth. If the diagnosis of antiphospholipid syndrome is confirmed, it is necessary to counsel and treat these women regarding future pregnancies.

KEY WORDS: Fetal death. Anticardiolipin antibody. Antiphospholipid syndrome.

\section{Referências}

1. Goel N. Antiphospholipid antibody syndrome: current concepts. Hosp Pract Off Ed 1998; 33: 129-30,1335,140 .

2. Asherson RA, Khamashta MA, Ordi-Ros J, Derksen RH, Machin SJ, Barquinero J. et al. The "primary" antiphospholipid syndrome: major clinical and serological features. Medicine 1989; 68:366-74.

3. Alarcón-Segovia D, Sanchez-Guerrero J. Primary antiphospholipid syndrome. J Rheumatol 1989; 16:482-8.

4. Levi RA. Diagnóstico, manifestações clíinicas e tratamento da sindrome do anticorpo antifosfolipídeo. Folha Méd 1996; 113:157-61.

5. Kwak JYK, Barini R, Gilman-Sachs A, Beaman KD, Beer AE. Down regulation of maternal antiphospholid antibodies during early pregnancy and pregnancy outcome. Am J Obstet Gynecol 1994; 171:239-46.

6. Tripplet DA. Assays for detection of antiphospholipid antibodies. Lupus 1994; 3:281-7.

7. Harris EN, Gharavi AE, Patel SP, Hughes GRV. Evaluation of the anticardiolipin antibody test: report of an international workshop held 4 April 1986. Clin Exp Immunol 1987; 68:215-22.

8. Asherson RA, Cervera R. Primary, secondary and other variants of the antiphospholipid syndrome. Lupus 1994; 3:293-8.

9. Ahlenius I, Floberg J, Thomassen P. Sixty-six cases of intrauterine fetal death. A prospective study with an extensive test protocol. Acta Obstet Gynecol Scand 1995; 74:109-17.
10. Moyo SR, Tswana SA, Nystrom L, Mahomed K, Bergstrom S, Ljungh A. An incident case-referent study of stillbirths at Harare Maternity Hospital: socio-economic and obstetric risk factors. Gynecol Obstet Invest 1994; 37:34-9.

11.Aquino MMA, Cecatti JG. Epidemiologia do óbito fetal em população de baixa renda. Rev Bras Ginecol Obstet 1998; 20:71-5.

12.Black KD, Ecker M, Librizzi RJ. Prevention of recurrent fetal loss caused by antiphospholipid syndrome. J Perinatol 1996; 16:181-5.

13.Lockshin MD, Druzin ML, Goei S, Qamar T, Magid MS, Jovanovic L et al. Antibody to cardiolipin as a predictor of fetal distress or death in pregnant patients with systemic lupus erythematosus. N Engl J Med 1985; 313:152-6.

14.Bocciolone L, Meroni P, Parazzini F, Tincani A, Radici E, Tarantini M, et al. Antiphospholipid antibodies and risk of intrauterine late fetal death. Acta Obstet Gynecol Scand 1994; 73:389-92.

15.Branch DW, Scott JR, Kochenour NK, Hershgold E. Obstetric complications associated with lupus anticoagulant. N Engl J Med 1985; 313:1322-6.

16.Branch DW, Silver RM. Criteria for antiphospholipid syndrome. Early pregnancy loss, fetal loss, or recurrent pregnancy loss? Lupus 1996; 5:409-413.

17.Silver RM, Pierangeli SS, Edwin SS, Umar F, Harris EN, Scott JR et al. Pathogenic antibodies in women with obstetric features of antiphospholipid syndrome who have negative test results for lupus anticoagulant and anticardiolipin antibodies. Am J Obstet Gynecol 1997; 176:628-33.

18.Gonzales CJ, Monedero M, Vinuesa M, Alvarez D, Digon J, Rodriguez JM. Abortions caused by anticardiolipin antibodies: prevention by low dose acetylsalicylic acid. Sangre 1997; 42:179-82.

19.Reece EA, Garofalo J, Zheng XZ, Assimakopoulos E. Pregnancy outcome. Influence of antiphospholipid antibody titer, prior pregnancy losses and treatment. J Reprod Med 1997; 42:49-55.

20.Harris EN, Gharavi AE, Boey M, Patel BM, MackworthYoung CG, Loizou S et al. Anticardiolipin antibodies: detection by radioimmunoassay and association with thrombosis in systemic lupus erythematosus. Lancet 1983; 2:1211-4.

21.Gharavi AE, Harris EN, Asherson RA, Hughes GR. Antiphospholipid antibodies: isotype distribution and phospholipid specificity. Ann Rheum Dis 1987; 46:1-6.

22.Urbanetz AA, Galloto Filho F, Kawai R, Dondoni R, Sampaio G. Óbito fetal intra-útero: análise de 176 casos. In: Anais do $15^{\circ}$ Congresso Brasileiro de Ginecologia e Obstetrícia; 1989; São Paulo, 1989. p. 45-6.

23. Axemo P, Liljestrand J, Bergstrom S, Gebre-Medhin M. An etiology of late fetal death in Maputo. Gynecol Obstet Invest 1995; 39:103-9.

24. Yetman DL, Kutteh WH. Antiphospholipid antibody panels and recurrent pregnancy loss: prevalence of anticardiolipin antibodies compared with other antiphospholipid antibodies. Fertil Steril 1996; 66:540-6. 